DIW BERLIN

Discussion Papers
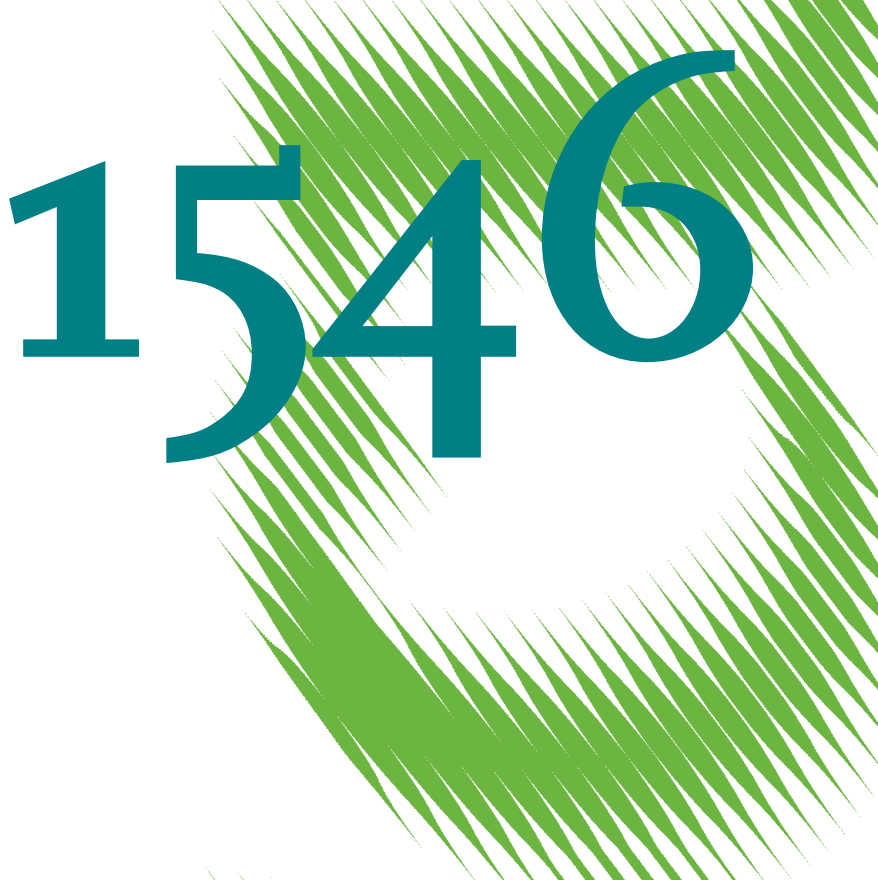

The Link between R\&D, Innovation and Productivity: Are Micro Firms Different? 
Opinions expressed in this paper are those of the author(s) and do not necessarily reflect views of the institute.

IMPRESSUM

(C) DIW Berlin, 2016

DIW Berlin

German Institute for Economic Research

Mohrenstr. 58

10117 Berlin

Tel. +49 (30) $89789-0$

Fax +49 (30) $89789-200$

http://www.diw.de

ISSN electronic edition 1619-4535

Papers can be downloaded free of charge from the DIW Berlin website:

http://www.diw.de/discussionpapers

Discussion Papers of DIW Berlin are indexed in RePEc and SSRN:

http://ideas.repec.org/s/diw/diwwpp.html

http://www.ssrn.com/link/DIW-Berlin-German-Inst-Econ-Res.html 


\title{
The link between R\&D, innovation and productivity: Are micro firms different?*
}

\author{
Julian Baumann $^{\dagger} \quad$ Alexander S. Kritikos ${ }^{\ddagger}$
}

February 4, 2016

\begin{abstract}
We analyze the link between R\&D, innovation, and productivity in MSMEs with a special focus on micro firms with fewer than 10 employees; usually constituting the majority of firms in industrialized economies. Using the German KfW SME panel, we examine to what extent micro firms are different from other firms in terms of innovativeness. We find that while firms engage in innovative activities with smaller probability, the smaller they are, for those firms that do make such investment, R\&D intensity is larger the smaller firms are. For all MSMEs, the predicted R\&D intensity is positively correlated with the probability of reporting innovation, with a larger effect size for product than for process innovations. Moreover, micro firms benefit in a comparable way from innovation processes as larger firms, as they are similarly able to increase their labor productivity. Overall, the link between $\mathrm{R} \& \mathrm{D}$, innovation, and productivity in micro firms does not largely differ from their larger counterparts.
\end{abstract}

Keywords: MSMEs, R\&D, Innovation, Productivity

JEL: L25, L60, O31, O33

${ }^{*}$ We are very grateful to Michael Fritsch, Adam Lederer, Enrico Santarelli, Alexander Schiersch, and Marco Vivarelli for their useful comments. We gratefully acknowledge the support of the Data Center of the Kreditanstalt für Wiederaufbau (KfW) in Frankfurt for providing us access to the KfW SME panel. The usual caveat applies.

$\dagger$ Julian Baumann is Researcher at the German Institute for Economic Research (DIW Berlin), email: jbaumann@diw.de

${ }^{\ddagger}$ Alexander S. Kritikos is Research Director at the German Institute for Economic Research (DIW Berlin), Professor of Economics at the University of Potsdam, and Research Fellow of the IZA, Bonn, and of the IAB, Nuremberg, email: akritikos@diw.de 



\section{Introduction}

Micro businesses - firms with fewer than 10 employees - are often associated with marginal businesses that have no growth options and limited R\&D investments. This assumption seems appealing, as it could be argued that these firms would become larger if they strive for innovation and more productivity. In this contribution, we therefore analyze to what extent micro firms put efforts into becoming more innovative. Information on the R\&D activities of micro firms is only rarely collected. For instance, the EU science and technology statistics, which are based on the Community Innovation Surveys (CIS) as well as many other data sources do not provide sufficient information on the innovative activities and the R\&D expenditures of micro firms.

Previous studies on SMEs, see inter alia Hall et al. (2009), therefore, exclude micro firms due to this lack of data. Relying on a version of the innovation model proposed by Crepon et al. (1998), they show that SMEs in all size classes above 10 employees contribute considerably to innovation output; ${ }^{1}$ some even without formal R\&D spending. Hall et al. (2009) further find that firm size is negatively correlated with R\&D intensity, but positively with the likelihood of having a process or product innovation, and that only product innovation has a positive impact on labor productivity.

As the majority of the firms are micro-businesses, the unique aspect of this approach is that we analyze the link between $\mathrm{R} \& \mathrm{D}$, innovation and productivity in MSMEs with a special focus on micro firms. Using the KfW SME panel, an annual survey conducted among a representative selection of micro-, small- and medium-sized firms in Germany, and employing the model of Crepon et al. (1998), we are able to test whether micro businesses unroll any innovation activities at all, either by spending money on R\&D or by unfolding other kinds of innovative endeavors. Secondly, if micro firms do have innovative activities, and a substantial share do, we are interested in investigating whether these decisions are proven

\footnotetext{
${ }^{1}$ Earlier studies that do not rely on the approach of Crepon et al. (1998) find similar results, see inter alia Acs and Audretsch (1987), Acs and Audretsch (1988), Acs and Audretsch (1990), Santarelli and Sterlacchini (1990), Hoffman et al. (1998), Kleinknecht (1987), Hall et al. (2009), Rammer et al. (2009); for developing economies see Chudnovsky et al. (2006).
} 
to be successful in the sense that we ask whether these efforts influence the probability of micro firms to realize a product or a process innovation. Third, we analyze whether the existing empirical evidence on the link between $R \& D$, innovation and productivity for larger firms is also valid for micro firms.

In line with the definition of the European Commission (European Commission, 2003), we consider firms with fewer than ten employees as micro-sized, while small-sized firms employ between 10 and 49; medium-sized have 50 to 249 employees. Figure 1, which is also based on CIS data, reveals the main contribution of our paper. ${ }^{2}$ It discloses that about $74 \%$ of all German firms in the manufacturing sector are micro-sized. The figure further shows the distribution of the share of firms reporting a process or product innovation: More than $90 \%$ of large companies report the introduction of a product or process innovation during a three year period, the share of medium-sized firms reporting innovation is is about $80 \%$ and about $65 \%$ in small firms; but the European innovation statistics lack information on innovative activities of micro firms. By including micro businesses in our analysis, we aim to close the gap in understanding innovation processes among the MSMEs. Shedding light on innovative activities of micro firms is not only interesting from a scientific point of view but can also provide crucial information for policy-makers who develop public support measures for R\&D in MSMEs.

We find that while firms engage in innovative activities with smaller probability, the smaller they are, for those firms that do make such investment, $R \& D$ intensity is larger the smaller the firm is. Our analysis further reveals that, regardless the size class, R\&D intensity has a positive effect on the probability of reporting an innovation, with a larger effect size for product than for process innovation. We also observe that a stable share among firms in all size classes (around one-quarter of all firms) report innovation without R\&D spendings. Moreover, unlike process innovation, product innovation has a sizable positive effect on firms' labor productivity. Micro firms benefit from this kind of innovation process in a comparable

\footnotetext{
${ }^{2}$ A similar figure is provided by Hall et al. (2009) for Italy, where $95 \%$ of all firms in the manufacturing and service sector are micro-sized.
} 
way that SMEs do, in the sense that their labor productivity increases by similar amounts.

The rest of the paper is organized as follows. In Section 2 we provide a theoretical background and briefly discuss previous empirical research approaches. Section 3 describes the data. Section 4 explains the econometric framework. In Section 5 we present our empirical results. Section 6 provides robustness checks and in Section 7 we conclude.

\section{Theoretical Background and Previous Research}

The manufacturing sector is a key industry in Germany, with many of its firms facing not only national, but also global competition. In order to remain profitable in such a competitive environment, firms need to constantly improve their productivity performance, through production cost reduction, with capital or labor growth, or by introducing innovative products or production processes. In this line, becoming more innovative is one promising way, albeit risky, to open new paths for growth processes. More specifically Griliches (1979) argues by introducing a knowledge production function, that such investments, if successfully made, may increase the stock of knowledge in a firm that may then lead to innovation, thus eventually improving the firm's output through increased productivity (see also Hall et al., 2010). At the same time, such investments bear the risk that firms fail to realize a positive return to their R\&D investment.

As we are focusing on micro firms, the questions arise as to whether micro firms - given this risk - refrain from starting any kind of innovative activities; are they indeed only marginal businesses with no growth option? Or are they able to manage such R\&D efforts to increase their stock of knowledge in order to become more innovative? And, if so, are they similarly successful as their larger counterparts in increasing their productivity?

From a theoretical point of view there are several reasons why few micro firms, if any, may decide to make such investments and why one would expect that the general relation between firm size, innovation and productivity would not work in the very same way for 
micro firms. ${ }^{3}$ Three reasons that we will shortly discuss here are: first, the differentiation of R\&D costs between sunk start-up costs and fixed costs (as introduced by Peters et al., 2013) leading to higher risks for firms making a first-time decision to invest in R\&D. Second, issues of information asymmetries between micro firms and external suppliers of finance, which may have the consequence that micro firms are impeded in their innovation activities due to credit constraint (Evans and Jovanovic, 1989, Czarnitzki and Hottenrott, 2011). And third, differing approaches to product and process innovation which may exist depending on firm size (Cohen and Levin, 1989).

One reason why smaller firms might be more likely to not invest in innovation is connected to the specific cost structure of R\&D investments and the risks linked to this decision. Previous research shows that investments into R\&D increase the probability of introducing a product or process innovation, but the probability that such investments will sufficiently increase a firm's future productivity is less than one (e.g. Griffith et al., 2006).

Thus, given the existing technological and economic uncertainties of such investments, firms may face a risk of failure, leading to negative returns on such R\&D investments. Peters et al. (2013) argue in their model that this problem is aggravated when firms decide to make R\&D investments for the first time. They differentiate between such first-time investors and those firms already experienced with $R \& D$, thus only deciding whether or not to continue their innovation activities. Those continuing these activities only have to make a decision whether to commit some fixed cost investments while beginners face greater "sunk start-up costs" (p. 12). As a consequence, first-time investors might be confronted with greater uncertainty with respect to these investments as the probability to realize positive returns is lower for them than for "repeaters." As micro firms have a higher probability to be potential first time R\&D-investors, they will decide with lower probability to enter such an investment path in comparison to the probability of repeaters to make one more round of R\&D-investment. ${ }^{4}$

\footnotetext{
${ }^{3}$ See Hall et al., 2010 and Peters et al., 2013 for a theoretical framework supporting these arguments.

${ }^{4} \mathrm{An}$ argument leading to similar effects is to point to the potential existence of thresholds. If investments into R\&D are indivisible beyond a certain amount, micro firms would suffer from such effects as they would have to invest relatively more money in comparison to larger firms just to pass such a threshold level. Again, they might face a non-positive return on their investment with higher probability.
} 
Therefore, we should observe a lower share of R\&D investments among micro firms.

Coming to the second reason, there is a positive relation between firm size and its financial performance. Micro firms may suffer more from information asymmetries than larger firms (Stiglitz and Weiss, 1981), thus probably facing liquidity constraints more often, as they are excluded from access to external finance. In contrast, larger firms might be better able to finance their R\&D investments using internal funds from undistributed profits or through an easier access to external finance (see Mairesse and Mohnen, 2002 and Conte and Vivarelli, 2014). Previous research further reveals that potentially innovative smaller firms are, at the same time, in greater need of external financing (Storey and Tether, 1998). This is especially relevant as micro firms cannot use internal funds from accumulated profits (Berger and Udell, 2002). Thus, some micro firms may simply not be able to finance R\&D investments, even if they theoretically would like to do so.

Overall, we should therefore expect that micro firms are less likely than larger firms to start an innovation process. On the other hand, for those micro firms deciding to make R\&D investment for the first time, the approach of Peters et al. (2013) predicts that these firms will have higher R\&D intensities. Moreover, we may also expect that, given the liquidity constraints more micro firms (compared to larger counterparts) might decide trying to become innovative with lower or no investments in $\mathrm{R} \& \mathrm{D}$.

Beyond the decision to start an innovation process based on $R \& D$ investments, there might be further reasons why firms may focus on a different kind of innovation processes depending on firm size. It is argued that larger firms might focus on process innovation more often than micro firms. Larger firms usually produce more output or products, thus having a higher degree of product diversification, an environment where it might make more sense to realize cost savings through process innovation (see Cohen and Klepper, 1996). Therefore, they argue that activities towards process innovation should depend more on firm size than product innovation and should be more likely with larger firms.

Excluding micro firms, the link between R\&D, innovation and productivity is empirically analyzed by a large stream of literature (for an overview see Mairesse and Mohnen, 2010, Hall, 
2011, or Mohnen and Hall, 2013). In their seminal paper, Pakes and Griliches (1984) find a statistically significant relationship between patent applications and $R \& D$ expenditures using data for 121 large US companies. Going beyond Pakes and Griliches (1984), later studies use richer micro data sets like the Community Innovation Surveys (CIS). Based on the Oslo Manual (OECD/Statistical Office of the European Communities, 2005) that proposes a standard practice for collecting and interpreting innovation data, the CIS are the main data sources for measuring innovation in Europe. The surveys are designed to obtain information on innovativeness on the firm level.

In order to take advantage of the structure of the CIS, Crepon et al. (1998) launched a structural model for estimating an extended knowledge production function. Later labeled as the $\mathrm{CDM}^{5}$ framework (Lööf and Heshmati, 2002), this model refines the standard knowledge production function approach of Griliches (1979) by analyzing various stages of the innovative process instead of directly estimating the relationship between $R \& D$ expenditures and productivity. Approaches in the spirit of Griliches (1979), like Harhoff (1998), who show that $\mathrm{R} \& \mathrm{D}$ is an important determinant for productivity growth in German manufacturing firms, provide strong evidence for the positive relationship between $R \& D$ and productivity. Building on this finding, the CDM model explicitly accounts for the fact that it is innovation output (and not innovation input) that increases productivity. In three equations it relates innovation output to productivity, the knowledge production function itself to $R \& D$ expenditures, and the $\mathrm{R} \& \mathrm{D}$ decision to its determinants. In an additional equation the CDM framework also corrects for the selectivity of $R \& D$ performing firms by explicitly modeling the choice of a firm of whether or not to engage in innovative activities. As the econometric model also corrects for the endogeneity of $\mathrm{R} \& \mathrm{D}$ and innovation output, the CDM model contributes to the analysis of the relationship between R\&D expenditures and productivity.

CDM models or variants of it are estimated (see Hall, 2011 for a survey), usually relying on CIS data, by Lööf and Heshmati (2002) for Sweden, Janz et al. (2004) for Germany and Sweden, Griffith et al. (2006) for Germany, Spain, the UK and France, Parisi et al. (2006),

\footnotetext{
${ }^{5}$ According to the authors' names, Crépon, Duguet and Mairesse
} 
and Conte and Vivarelli (2014) for Italy, Hall et al. (2009) for Italian SMEs, García-Quevedo et al. (2014) for Spain with differing effects for older and younger firms, and in a cross-country comparison for 18 OCED countries by Criscuolo (2009).

Most of these approaches use $R \& D$ expenditures as a proxy for innovation input and assume the existence of simultaneity between $\mathrm{R} \& \mathrm{D}$, innovation, and productivity. Although the magnitude of the effect of $R \& D$ on innovation differs across the studies, one consistent finding is that the likelihood of being an innovator is positively associated with the R\&D intensity. While this result might not be surprising when using a dichotomous innovator variable, the CIS data additionally reveal that some firms do not innovate despite engaging in $\mathrm{R} \& \mathrm{D}$, clarifying that $\mathrm{R} \& \mathrm{D}$ investments are risky, while other firms are innovative without formally budgeting for R\&D.

Furthermore, it should be highlighted that most studies find only a positive impact of product innovation on labor productivity, at least when using a dummy variable for innovation. ${ }^{6}$ In contrast, when approaches control for product innovation, the effect of process innovation often turns out to be insignificant or even negative. Hall (2011) suggests that this result might be due to a correlated measurement error that leads to an upward bias for the better measured product innovation and a downward bias for process innovation.

In a novel approach, instead of relying upon the CDM framework, Peters et al. (2013) estimate a dynamic structural model to quantify the payoff to $R \& D$ investments using firmlevel panel data from the German manufacturing sector. ${ }^{7}$ In contrast to the CDM approach, they explicitly model a firm's demand to $R \& D$, estimating its cost and long-term payoff. Concerning the relationship between innovation input and its output, they also find that R\&D investments increase the probability of a product or process innovation. Moreover, like previous studies relying on a CDM model or its variants, they show that firms can be successful innovators without R\&D investment. Additionally, by exploiting the panel

\footnotetext{
${ }^{6}$ One exception is Mairesse and Jaumandreu (2005), who confirm this finding, although they estimate changes in productivity using revenues and output deflated prices.

${ }^{7}$ This approach is based on Doraszelski and Jaumandreu (2013), who develop an endogenous productivity model to analyze the role of R\&D investments for firm-level productivity in the long-term.
} 
structure they report that past $R \& D$ investments are a strong predictor for current $R \& D$ investments. Last, but not least, they reveal that there is, but only for the median hightech firm, a positive return to $R \& D$ investments, while the median low-tech firm realizes a negative return to this investment. The latter result is important for our approach. Setting micro firms that have not yet been investing in R\&D equal to low-tech firms, shows that such an investment strategy might be particularly risky for them.

The first study we identify that investigates the link between $R \& D$, innovation and productivity in SMEs - excluding micro-sized firms - is Hall et al. (2009). Like Griffith et al. (2006), they modify the original CDM model by including separate dummies for product and process innovation. They find that firm size is negatively correlated with R\&D intensity but positively with the likelihood of reporting an innovation. R\&D intensity itself has a strong effect on the ability of SMEs to report product or process innovation, while only product innovation is directly and positively associated with SMEs' labor productivity.

Building on these findings, we explicitly analyze, based on a modified CDM model, to what extent micro firms are successful in trying to innovate, both with or without formal R\&D spending, and to what extent the generally existing empirical evidence on the relationship between R\&D, process and product innovation, and productivity also applies to a sample that includes micro-sized firms. In contrast to previous approaches, we run separate regressions for firms with less than ten FTE employees.

\section{Data}

This paper uses the KfW SME panel ( $K f W$ Mittelstandspanel), which is a representative survey of micro, small and medium-sized firms in Germany that have an annual turnover of up to EUR 500 million. Participation in the KfW SME panel is voluntary. The survey waves, with a response rate around 20\%, contain between 9,000 and 15,000 observations. Like similar surveys in other countries, the KfW survey asks for information covering up to three years preceding the interview. One portion of the data is collected quantitatively, 
such as firms' investment, share of R\&D in total sales, number of employees as well as sales for the current and previous years. Data on innovation indicators are mainly collected via dichotomous variables. ${ }^{8}$ In this line, the KfW SME panel asks for two different types of innovative outcomes, i.e. product- and process innovation, which are measured by dummy variables. A special feature of the KfW SME panel is that it includes micro enterprises with fewer than ten employees, which we take advantage of as it facilitates an examination of micro firms.

In our approach we make use of all waves from 2005 through $2012 .{ }^{9}$ After restricting the sample to firms with fewer than 250 employees and an annual turnover less than EUR 50 million, in order to adhere to the European Commission's definition of MSMEs, ${ }^{10}$ it consists of 16,579 observations of manufacturing firms (see Table I). While $60 \%$ of the medium-sized companies report engagement in R\&D, the share decreases with the firm size down to $19 \%$ for micro firms. Unfortunately, we are able to use the data only as pooled cross sections, not as a panel. One reason is that of the 4463 observations for micro firms, (corresponding to 1982 different firms), about $47 \%$ of the firms are observed only once and another $21 \%$ only twice. Moreover, in order to ensure that R\&D engagement is realized strictly before the reported innovative outcome, the sample size would even shrink further, resulting in a sample size too small for reliable panel estimation. ${ }^{11}$

Although covering a different time span, the share of SME firms reporting at least one product and/or process innovation is virtually the same as in the CIS 7 (refer to Figure 1), thus supporting the reliability of the KfW dataset. According to the definition in the Oslo manual, $78 \%$ of the medium-sized firms in the KfW SME panel are innovators (compared to $79.9 \%$ in the CIS 7$)$ while $63 \%(64.7 \%)$ of the small-sized firms report being innovative. The KfW SME panel makes it possible to fill the gap concerning the innovator share for firms

\footnotetext{
${ }^{8}$ For a detailed description of the survey in German, see Schwartz (2013).

${ }^{9} \mathrm{We}$ exclude the first wave from our analysis because only firms that reported an innovation had to answer R\&D related questions. The second wave is not included because it does not contain information on $\mathrm{R} \& \mathrm{D}$ expenses.

${ }^{10}$ We define the sub-categories, i.e. micro, small and medium enterprises by the number of employees only.

${ }^{11}$ For a further discussion of this issue, see Section 6.
} 
with fewer than 10 employees. Table I shows that the innovator share is $53 \%$ in firms with 5-9 employees, and 39\% for the smallest firms with fewer than 5 employees.

This observation shows that almost every second micro firm is trying to innovate, even if about half of these innovators are classified as innovators without formal R\&D expenditures. Interestingly enough, the share of MSME firms reporting innovation without R\&D engagement is stable over all size classes, i.e. ranging between $23 \%$ and $28 \%$, and does not further increase for micro-sized enterprises compared to small or medium-sized companies. Moreover, while $3 \%$ of micro-sized firms report R\&D engagement without a successful process and/or product innovation, this share is also constant across all size classes. Furthermore, between $21 \%$ of firms with fewer than 5 employees and $58 \%$ of medium-sized firms have introduced a process innovation during the last three years. Following the definition in the CIS, a process innovation in the KfW SME panel is defined as a new or significantly improved production process, where the term "new" refers to new to the company but not necessarily to the market (see also Scherer and Harhoff, 2000). Similar to process innovation, a larger share of medium-sized firms $(66 \%)$ report the introduction of a new or significantly improved good or service (product innovation) compared to $32 \%$ of the micro firms. In line with theoretical considerations, we also see a slight tendency that the share of process innovators among all innovators increases with firm size.

- insert Table I about here -

Table I provides further information. With respect to the age of firms, we observe an age gradient in the sense that the larger the firms, the older they are: At the time of the survey $53 \%$ of the smallest firms were younger than 15 years. Around $27 \%$ were between 15 and 35 years, while $20 \%$ were founded more than 35 years before their respective survey year. Small- and medium-sized companies are more frequently older than 35 years (34\% and $48 \%$ respectively) than micro-sized firms, showing that among micro firms the share of young firms is somehow higher than among larger companies.

The main sales market varies - as expected - with the size of the firm: for more than $69 \%$ of 
all firms with less than 5 employees it is regional, with only $5 \%$ reporting an international main sales market. With increasing company size, relatively more firms report an international main sales market (12\% small-sized, 21\% medium-sized firms). Last, but not least, larger firms are more likely to belong to a group of firms (between $7 \%$ and $26 \%$ ). And while the share of high skilled employees is roughly constant between 11-13\% over all size classes, the investment intensity as well as the R\&D intensity, which is measured as R\&D expenditures per FTE employee, conditional on firms making investments (R\&D expenditures) decrease slightly with size class. ${ }^{12}$

\section{Model}

Since the work of Pakes and Griliches (1984) and with the introduction of CIS-style innovation surveys, structural models are used to examine the relationship between R\&D effort, innovation output and productivity. To analyze these relationships for MSMEs in Germany, we estimate a modified CDM model. Different from the original CDM model estimated for innovative firms only (in terms of positive R\&D expenditures), we follow Griffith et al. (2006) and assess the model for all firms, including the non-innovative ones. Similar to Hall et al. (2009), we try to improve on Griffith et al. (2006) by estimating process and product innovation simultaneously with a bivariate probit model.

Although the CDM model is explained in previous approaches (see appendix of Hall, 2011, for an overview), we briefly outline its intuition and our basic framework, as related to Hall et al. (2009). Originally proposed by Crepon et al. (1998), the CDM model is a workhorse model estimating the relationship between innovation input, its output and productivity. The modified CDM model in this paper comprises three steps. The first step, which is formalized in Equation 1, accounts for firm $i$ 's innovative effort $i e_{i}^{*}$

\footnotetext{
${ }^{12}$ Although different indicators, the fact that the $\mathrm{R} \& \mathrm{D}$ intensity is nearly as large as the investment intensity for some size classes might cast some doubt on the data quality. However, the way of asking the questions might serve as an explanation for this finding: while investment intensity is asked directly in the survey, R\&D expenditures are measured as the share of total sales, which may cause measurement errors.
} 


$$
i e_{i}^{*}=X_{i}^{\prime} \beta+\varepsilon_{i}
$$

where the innovative effort is proxied by the R\&D intensity of a firm (that is R\&D expenditures per full time equivalent employee), while $X_{i}$ denotes a vector of determinants of innovative efforts and $\varepsilon_{i}$ the error term. ${ }^{13}$

Our sample includes all firms and not just R\&D performers. Consequently, as R\&D expenses can be measured only if firms report such expenditures, simple estimation of Equation 1 would bear the risk of selection bias. To correct for the endogeneity, we test for selection using Heckman's selection model (Heckman, 1979) before estimating Equation 1. Formally, we account for the possible selection into R\&D in Equation 2.

$$
\operatorname{sie}_{i}= \begin{cases}1, & \text { if sie } e_{i}^{*}=X_{i}^{\prime} \alpha+e_{i}>\hat{c} \\ 0, & \text { if sie } \text { si }_{i}^{*}=X_{i}^{\prime} \alpha+e_{i} \leq \hat{c}\end{cases}
$$

As an indicator function, the selection into innovative effort, $s i e_{i}^{*}$, equals one if firm $i$ 's R\&D intensity exceeds a certain threshold, $\hat{c} . X_{i}$ denotes a vector of variables explaining the R\&D decision and $e_{i}$ the error term. Conditional on firm $i$ 's decision to invest in $\mathrm{R} \& \mathrm{D}$, we then specify the equation for estimating the R\&D intensity as follows:

$$
i e_{i}= \begin{cases}i e_{i}^{*}=X_{i}^{\prime} \beta+\varepsilon_{i}, & {\text { if } \text { sie }_{i}=1}_{0,} \\ \text { if } \text { sie }_{i}=0\end{cases}
$$

where $i e_{i}^{*}$ is the unobserved latent variable reflecting $\mathrm{R} \& \mathrm{D}$ intensity and $X_{i}$ a vector of explanatory variables. Under the assumption, that the error terms $e_{i}$ and $\varepsilon_{i}$ are univariate normal with zero mean and independent of the explanatory variables, we can estimate the system of Equations 2 and 3 as a Heckman selection model in a two-step estimation.

\footnotetext{
${ }^{13}$ Like previous approaches (see Hall, 2011 for an overview), due to data limitations we proxy innovative effort with the current R\&D intensity. Implicitly this proxy is based on the assumption that firms' R\&D engagement and intensity persists over time (for evidence in this direction see Peters, 2009; Peters et al., 2013, and García-Quevedo et al., 2014.) The same consideration applies to the use of current innovative output as a proxy for knowledge and investment intensity as a proxy for capital stock.
} 
In the second step of the CDM model, the predicted R\&D intensity from step 1 is included as an explanatory variable in a bivariate probit model in order to estimate the probability of having a process or product innovation. As displayed in Table I, around $25 \%$ of all firms report, regardless of size class, innovative activities, even if they do not engage in formal R\&D. To account for the possibility that firms may be involved in some R\&D activities without reporting it, we use the estimated instead of the observed $R \& D$ intensity as an explanatory variable in the second stage. We analyze process and product innovations with the following two separate equations

$$
\left\{\begin{array}{l}
p d_{i}=i e_{i}^{*} \gamma+Z_{i}^{\prime} \delta_{1}+u_{1 i} \\
p z_{i}=i e_{i}^{*} \gamma+Z_{i}^{\prime} \delta_{1}+i i_{i} \delta_{2}+u_{2 i}
\end{array}\right.
$$

where the acquired knowledge proxied by the product and process innovation indicators is represented by $p d_{i}$ and $p z_{i}$ and the predicted innovative effort by $i e_{i}^{*}$. Furthermore, $Z_{i}$ denotes a vector of several knowledge explaining variables, $i i_{i}$ the investment intensity and $u_{1 i}$ and $u_{2 i}$ the error terms. Following Hall et al. (2009), in order to consider that process and product innovation might be influenced by the same unobservable firm characteristics, we estimate Equation 4 with a bivariate probit model.

By using the predicted value instead of the observed R\&D intensity, we not only include non-reporting R\&D firms in the model, but we additionally consider that innovative effort is most likely endogenous to the knowledge production function. In other words, we would encounter an endogeneity problem if there were unobservable characteristics that were correlated with both the innovative effort (of stage 1) and the knowledge production (of stage 2). More formally, endogeneity would imply that $i e_{i}^{*}$ and $u_{i}$ were correlated, which in turn causes a biased estimate for $\gamma$. However, under the assumption that $X_{i}$ is independent from $u_{i}$, we can correct for the possible endogeneity by using the estimated innovative effort.

Finally, the last step of a CDM model is the estimation of a productivity function. For the productivity Equation 5, we use a Cobb-Douglas function with constant returns to scale. 


$$
y_{i}=p d_{i}^{*} \pi_{1}+p z_{i}^{*} \pi_{2}+i i_{i} \pi_{3}+W_{i}^{\prime} \pi_{4}+v_{i}
$$

The dependent variable $y_{i}$ denotes the labor productivity measured in sales per full time equivalent employees in logs. As explanatory variables, we use proxies for knowledge and capital. While $i i_{i}$ represents the investment intensity, the predicted probability for product innovation $p d_{i}$ and process innovation $p z_{i}$, i.e. the marginal success probability for the product/process innovation equations, are used as proxies for knowledge creation. Finally, we also include a vector of additional control variables, $W_{i}$, in the equation. Again, we take care of potential endogeneity of product and process innovation by using the predicted values from step 2. We estimate Equation 5 via OLS.

Steps 2 and 3 use the predicted values of the preceding step in order to address endogeneity and to account for the fact that some innovative firms might engage in R\&D (or innovation) without reporting it in the survey. Thus, in line with the original CDM model, the theoretical framework corrects for selectivity and endogeneity. This means that the model corrects for the fact that firms that are engaged in $R \& D$ are a nonrandom subset of all firms and that successful innovators might be those firms that also spend more on R\&D. As we estimate all equations sequentially, we use bootstrapped standard errors in order to derive consistency.

\section{Results}

In this section we present the estimates of the CDM model described in the previous section. We estimate the model on the full sample as well as separately on micro firms and larger SMEs in order to allow for heterogeneous effects between size classes. We start by testing for selection into R\&D using Heckman's selection model. Based on the predicted innovative effort we then present the results for the knowledge production. Finally, we show the estimates for the determinants of the labor productivity. 


\section{Stage: Innovative effort}

The results of Equation 3 are presented in Table A2 in the appendix. Column 1 displays the estimation results for the full sample. The estimated coefficient lambda (inverse Mills ratio), which takes account of the possible selection bias, is -0.069 . However, it has a corresponding p-value of 0.86 possibly implying that the hypothesis of uncorrelated error terms cannot be rejected. It follows that we do not find a significant selection bias into R\&D for German MSMEs (like Hall et al., 2009 for Italian SMEs). ${ }^{14}$

Yet, this conclusion must be treated with caution as without an exclusion restriction (i.e. variables affecting the decision to invest in $R \& D$, but not the intensity of the innovation effort) the identification of the selection model is only based on the nonlinearity in the functional form. In fact, a likewise plausible interpretation would be to argue that the estimator does not capture the selection bias, implying a potential problem with selection. However, as we cannot convincingly rule out selection effects without an exclusion restriction and keeping in mind that the Heckman two-step estimation suffers from inflated standard errors under this condition (Puhani, 2000), we follow Hall et al. (2009) by estimating the innovative effort on the whole sample without correcting for selection bias.

\section{- insert Table II about here -}

The results of Equation 1 are shown in Table II. Column 1 displays the results for the full sample with medium-sized firms, a regional sales market, and firms younger than 15 years serving as reference group. First, when relating expenditures to employees, we observe that larger SMEs have a lower R\&D intensity than smaller ones: small firms invest $36 \%$ more in R\&D per employee than medium-sized firms, firms with 0-4 FTE employees invest, ceteris paribus, $90.4 \%$ more in R\&D per employee than in medium-sized firms. ${ }^{15}$ Secondly, we observe that firm age has a significantly negative effect for firms older than 35 . Thus, relatively young firms tend to put more effort per FTE into innovative activities than mature

\footnotetext{
${ }^{14}$ The same argumentation applies to micro firms (Column 2) and larger SMEs (Column 3).

${ }^{15}$ Following Halvorsen and Palmquist (1980) and Kennedy (1981), we calculate the percentage changes for the dummy variables in Stage 1 and Stage 3 as $\exp (\hat{\beta}-0.5 \hat{V}(\hat{\beta}))-1$ where $\hat{\beta}$ is the respective estimated coefficient and $\hat{V}(\hat{\beta})$ its estimated variance.
} 
firms. We are further able to confirm previous discussion of whether global players are more innovative than local players. We observe that national and international main sales market is positively correlated with R\&D intensity. Given that the dependent variable is in logs, an estimated coefficient of 0.806 for firms that mainly sell their products internationally implies that their R\&D intensity is, ceteris paribus, 1.23 times larger than for mainly regionally active firms. This observation is in line with previous findings, where the positive relationship between export activity and R\&D intensity is unanimously shown (e.g. Hirsch and Bijaoui, 1985 for Israel, Hall et al., 2009 for Italian SMEs or Arnold and Hussinger, 2005 for German manufacturing firms).

Looking at the estimation results for micro firms in Column 2 and for firms with more than 10 FTE employees in Column 3 of Table II, we observe that the R\&D intensity remains constant among micro firms, i.e. it does not depend on the number of FTE employees. Among larger firms above 10 FTE employees, the negative relationship between R\&D intensities and firm size is confirmed. We further reveal that older firms among micro firms spend relatively higher innovation efforts, while we observe no such change among larger SMEs. To the contrary: the previously mentioned reduction of R\&D intensity among older firms (above 35 years) holds only for firms with more than 10 FTE employees.

\section{Stage: Knowledge production}

Table III shows the results for Equation 4 for the full sample. It provides us with answers to what extent the knowledge production was successful, or more specifically whether R\&D investments lead to process or product innovations. As we estimate the model sequentially, we report bootstrapped standard errors. The bootstrap is implemented by estimating the two equations for innovative effort and knowledge production on samples drawn from the data with 200 replications. The estimated correlation coefficient $\rho\left(=\operatorname{Cov}\left(u_{1 i}, u_{2 i}\right)\right)$ is positive and significantly different from zero. This finding confirms the assumption that process and product innovation are indeed affected by the same unobservable characteristics.

- insert Table III about here - 
Interpreting the average marginal effects, a doubling of predicted $R \& D$ intensity, is correlated with a 12 percentage points ( $\mathrm{pp}$ ) increase in the probability of a process innovation and a $29 \mathrm{pp}$ increase in the probability of reporting a product innovation. We also observe that firm size is positively associated with successful innovative activities. ${ }^{16}$

Furthermore, a larger investment intensity and relatively more high skilled employees are positively correlated with process innovation. Notably, the effect of high skilled employees on product innovation is even stronger. Finally, we further reveal a significantly positive effect of firm age on product innovation.

To further analyze the link between $\mathrm{R} \& \mathrm{D}$ and innovation activities, and to reveal whether this link is different for micro firms as compared to their larger counterparts, we also estimate Equation 4 for the two size classes separately. Table IV shows the results for micro firms, Table V for larger SMEs.

\section{- insert Tables IV and V about here -}

In general, we observe similar effects for both size classes: Increasing the R\&D intensity increases for micro and larger SME firms more strongly the probability of a product than of a process innovation. Moreover, the number of FTE employees and the number of high skilled employees have a positive effect on this probability, again for both size classes. However, there are also important differences between micro firms and other firms. While we observe a negative effect of firm age on the probability for a successful innovation for micro firms, the positive effect of firms older than 35 years on product innovation holds only for larger SMEs.

\section{Stage: Labor productivity}

The estimation results of Equation 5 are presented in Table VI. This estimation focuses on the central question to what extent the successfully installed (process or product) innovation influences the firms' labor productivity. Column 1 displays the results for the full sample. The reference groups are medium-sized firms and firms younger than 15 years. Specifically,

\footnotetext{
${ }^{16}$ We should emphasize that given the use of dummy variables for a successful innovation, the reported lower probabilities should be interpreted with great caution. We return to this point in Section 6 .
} 
the productivity level of a product innovator is substantially higher than that of a nonproduct innovator. In contrast, the estimated coefficient of process innovation is positive but not significant.

- insert Table VI about here -

Looking more deeply into the effects of different size classes (Column 2 and Column 3), we observe for micro firms a stronger effect of product innovations on their productivity level. The effect of process innovation on labor productivity remains insignificant for both size classes, but it turns out to be negative for micro firms. ${ }^{17}$ We also observe an interesting firm age effect. Although mature firms appeared to be less innovative, we reveal that labor productivity increases with firm age (as it also does with investment intensity), in particular among micro firms.

\section{Robustness Checks and Limitations}

In this section we first discuss two concerns regarding the estimation of product and process innovation and conduct various robustness checks, before turning to the limitations of our approach.

With respect to the estimation of Equation 4, which describes the knowledge production function, we use investment intensity as explanatory variable only for process innovation but not for product innovation (like Hall et al., 2009). As we cannot support this decision with economic theory, we also include the investment intensity to the product innovation equation as a robustness check. As shown in Table A3 in the appendix, investment intensity has a significant effect only on the probability of a process but not on a product innovation. Furthermore, comparing Table A3 with Table III reveals that the inclusion of investment intensity in both equations only marginally affects the other point estimates.

\footnotetext{
${ }^{17}$ We should point to another observation as well: at least among MSMEs (having excluded large firms), firms seem to become significantly more productive the smaller they are. This somehow counterintuitive observation is also reported by Hall et al. (2009) for Italy. For a detailed discussion on this issue please refer to Section 6.
} 
Our second concern in the estimation approach regards the fact that both product and process innovation are predicted from the same exogenous variables, which is why it is difficult to separately identify the effects. In this line, Hall (2011) suggests that the insignificant result of process innovation on productivity might be due to a correlated measurement error that leads to an upward bias for the better measured product innovation and a downward bias for process innovation.

For this reason we also estimate the effect of being an innovator instead of separating the effects of product and process innovations. The analysis of the full sample (see Table A4) reveals that the sign and effect size of each predictor is similar to our main specification in Table III. The same observation holds true for micro firms (Table A5) and for larger SMEs (Table A6) when knowledge production is proxied by being any type of innovator. Notably, as in our main specification, we observe one major difference between micro and larger firms. While micro firms between 15 and 35 years of age are less likely to be successful innovators, larger SME firms that are older than 35 years are significantly more successful in creating innovative output.

Moreover, instead of disentangling the effects of product and process innovation on labor productivity (as in our main specification in Table VI), Table A7 shows the effect of being an innovator on labor productivity. While the effects of firm age and investment intensity remain similar in magnitude in the full sample (Column 1), as well as for micro firms (Column 2) and larger firms (Column 3), the magnitude of the effect of innovation on labor productivity is similar across micro and larger firms. Thus, both robustness checks confirm our main findings presented in section 5 and offer a clear answer to our main research question. Micro firms benefit from investments into innovation processes: the within size-class comparison shows that they succeed in increasing the labor productivity among innovators in a similar way as do their larger counterparts.

There are three further issues staked out in this paper that need discussion when analyzing the link between R\&D investment, innovation and productivity, issues that constitute the limitations of the paper. 
First, when it comes to the interpretation of the results, we must highlight that this study relies on cross-sectional data and, therefore, implicitly assumes simultaneity between innovation input, its output and productivity. As mentioned by Hall (2011) this concern applies to most studies using a CDM model. ${ }^{18}$

The reason we are not able to exploit the panel structure in our case is that questions concerning the innovative behavior cover the last three years, while information on $R \& D$ expenditures and sales is available from all waves on an annual basis. Thus, to ensure that R\&D engagement is realized strictly before the reported innovative outcome, we would need to use a three years lag of the $R \& D$ variable, leading to a sample size too small for precise estimation. $^{19}$

Therefore, as we have to ignore the timing between R\&D, innovation and its possible impact on productivity in our cross-sectional setting, the correlations we are finding do not necessarily reflect causal relationships. However, it is encouraging that we find evidence that micro firm R\&D engagement is also persistent. As mentioned in Section 4, using current R\&D spending as a proxy for innovative effort is based on the assumption that firms' R\&D behavior persists over time. We also find that among micro firms reporting R\&D expenses in a previous survey wave is a strong predictor for current $R \& D$ investments, which indicates a persistent in the $R \& D$ behavior. Once a micro firm reports $R \& D$ expenses for the first time, the average probability of reporting it in every future wave is little less than $70 \%$.

The second concern regards information on process and product innovation, which is based on dummy variables instead of a continuous measure like the innovative sales share. This limitation strongly affects the measurement of innovation when differentiated by firm size. In other words, as larger firms are more likely to report at least one innovation, the proxy for knowledge production is vulnerable to measurement error. Consequently, as we have to use a binary variable for innovation, the informative value of the connection between

\footnotetext{
${ }^{18} \mathrm{An}$ exception is Belderbos et al. (2004). Interestingly, their observations do not differ from results based on cross-sectional data. Moreover, Peters et al. (2013), whose approach is not based on a CDM model confirm the main findings using panel data.

${ }^{19}$ While $47 \%$ of micro firms in our sample participate once in the survey, only $13 \%$ participate in at least four out of eight waves.
} 
firm size and innovation must be cautiously interpreted.

Currently, we have no doubt that a substantial share of micro firms invest in $R \& D$, although the share is considerable smaller than for larger firms. Moreover, micro firms (relative to other firms in the same size class) are as successful as larger SMEs in turning innovative input into innovative output. Likewise (again in a within size-class-comparison), knowledge, proxied by innovation, has the same size effect on firms' productivity for micro firms and for larger SME firms.

In contrast, we should be rather cautious in interpreting the firm size class dummies in a comparison between different size classes. In particular, the use of intensities in stage 1 and stage 3 might bias the firm size effect towards micro firms while measuring innovation with a dummy variable (stage 2) favors larger firms.

Third, while our data set is the first to contain information on micro firms, the same data have limitations with respect to some other important variables. We have no information on the fixed capital stock variable. Instead, we approximate it using investment intensity (as in previous research, e.g. Griffith et al., 2006, and Hall et al., 2009). Still, the problem with this proxy is that it might overstate the actual capital stock available in small and young firms. Moreover, we do not have information on material input variables either. As the share of material input might vary significantly by size, it might also influence our productivity measures, as we compute productivity by sales over employees. Last but not least, this productivity measure might be sensible to differing size classes. Hence, the missing information may distort our results when making comparisons between different firm sizes.

Putting the second and third limitation together, there are thus several reasons why those results which compare effects between different firm size classes in the full estimation results (in Tables III and VI as well A3, A4 and A7) might be driven by measurement errors. This affects the findings at the second stage of our approach that micro firms have lower probabilities in turning knowledge into innovation than larger firms, and at the third stage of our approach that micro firms are relatively more productive than their larger counterparts. Therefore, we refrain from interpreting these results any further. 


\section{Summary, Conclusions and Further Research}

In this study we analyze the link between R\&D, innovation, and productivity in all firm size classes below large firms in the German manufacturing sector, i.e in micro-, small- and medium-sized enterprises (MSMEs). Due to a lack of data, prior research on innovation could not analyze how innovative inputs translate into knowledge and productivity in micro firms. The present study closes this gap by estimating a structural model based on Crepon et al. (1998) in order to investigate through which channels micro firms - in relation to larger SME firms - foster their innovative output and productivity.

We find that the share of German micro firms engaged in innovative activities is around $50 \%$, thus, as expected in theory, below the share of larger SME firms, but still far above zero. Further differentiating between innovation activities with and without formal R\&D spending, we also observe that the share of firms reporting innovation without $R \& D$ engagement is constant at around $25 \%$ for all firm sizes. This is remarkable, as there is the implicit expectation that among micro firms there might be a larger share reporting innovation without formal R\&D engagement (see Pavitt et al., 1987).

Those micro firms that do invest in innovation activities have more than $90 \%$ higher R\&D expenditures per employee than do medium-sized firms. Thus, firm size is negatively correlated with R\&D intensity. This observation was also found in earlier studies for SMEs, and is confirmed when micro firms are added, pointing to the theoretically discussed problem that micro firms may face relatively higher costs than their larger counterparts when they decide to make R\&D investments. Of course, with our data we cannot answer the question whether there are indivisibility issues, which would mean that micro firms face relatively higher costs each time they make such a decision or whether these higher costs appear only once, i.e. micro firms make an R\&D investments for the first time. Both potential explanations are captured by our empirical analysis, but the findings of Peters et al. (2013) speak more in favor higher start-up costs that only appear once. Nevertheless, it should be addressed in future research whether micro firms do face due to their smallness specific 
indivisibility issues.

We further observe that micro firms are, at the second stage, similarly successful as larger SME firms in turning R\&D investments into innovation and at the third stage in directing innovation into higher productivity levels. Thus, overall, micro firms are not doing worse than their larger counterparts in turning their knowledge into productivity. We should emphasize, however, that these comparative effects include comparisons only within but not across firm size classes. That is, within each firm size class we observe a similar positive correlation of innovative effort, proxied by $\mathrm{R} \& \mathrm{D}$, and knowledge production. ${ }^{20}$

Differentiating between different innovation processes, it is in particular product innovation that has a sizable effect on labor productivity, clarifying how important this kind of effort is for productivity growth and, thus, for firms aiming to remain or become competitive. In contrast to the product innovation effect, we could not find a significant effect of process innovation on sales per FTE employee, and this holds for all firm sizes. ${ }^{21}$

Although data and methods used vary substantially, there are some findings that are consistent throughout many papers. Like Hall et al. (2009) for Italian SMEs, we find that R\&D intensity is fostered by international competition and being part of a group of companies, while larger and, to some extent, older firms have a lower R\&D intensity. We confirm these results having used a dataset that includes micro firms, and reveal that the age effect is driven by larger firms above 10 FTE employees. Apart from this, we show that being a micro firm has positive effect on the R\&D intensity as well. Also consistent with the empirical evidence, $R \& D$ has a sizable influence on firms' ability to introduce an innovation, with the effects being stronger on product than on process innovation. Finally, high skilled employees and investments in new equipment and machinery positively influence the probability of introducing an innovation.

Our results point to several further topics which also need to be addressed in future

\footnotetext{
${ }^{20}$ As discussed in the limitations section, we have to be very cautious in stating that larger SMEs are more likely to report innovation, as the observation might be driven by the use of the dummy variables.

${ }^{21}$ However, we should emphasize that the insignificant effect of process innovation might be due to a correlated measurement error that leads to an upward bias for the better measured product innovation and a downward bias for process innovation.
} 
research. Most importantly, it would be crucial to know to what extent the R\&D investments of micro firms turn out to be profitable in terms of higher net revenues in the short- and long-run in comparison to those micro firms not making such investments. Future research should also address the question of whether those firms who are not entering the path of innovation are deciding against it because they deliberately aim to avoid the risks connected with this choice or because they face liquidity constraints. Depending on the answers at these questions, it should be decided whether there is need of policy measures that encourage or even financially support micro firms in engaging in innovative activities.

Furthermore, we face some limits with respect to gathering information on innovation outcomes and on the timing of gathering that information. For that, we need better longitudinal data to get beyond a cross sectional analysis of firms' innovative activities and more sophisticated measures of innovation outcomes taking also the size of the innovation into account. Having open access to better panel data would also allow us to address the following three questions. First, is there any specific age level where most (micro) firms decide to become or not to become innovative? Which role does innovation play for later growth processes of micro firms? And can the so called gazelles - fast growing very innovative firms be identified among the young micro firms or do such firms start larger from the beginning? Our research results point at least to an interesting age effect: young micro firms (less than 15 years old), although they have lower R\&D intensities, realize with higher probability an innovation outcome than micro firms aged between 15 and 35 years and it would be important to find out how such young innovative micro firms further develop in the future.

Based on our findings first policy conclusions can be drawn. The most general policy advice would be that micro firms should not be set equal to marginal businesses with no growth option. There is a substantial share of innovators among them. Secondly, if policies should be directed towards increasing the labor productivity of firms, then public support should probably be channeled into directions where innovative activities are heading for product innovation. This holds the more as there is also some evidence that process innovation could be rather job-destroying, while product innovation implies the creation of new jobs (see 
Vivarelli, 2015, for an overview).

Thirdly, young micro firms, in particular when they are innovative, add to the level of competitiveness of an economy either by bringing in own new product ideas or by an indirect competition-enhancing effect according to which they push established firms to improve their performance through innovation activities. In this sense, it should be critically evaluated to what extent the entry of new firms into and their exit from markets is impeded through (over-)regulation.

In conclusion, this analysis provides evidence that the existing knowledge on the link between $R \& D$, innovation and productivity can be transfered to firms that have fewer than ten employees. In fact, the channels that make innovation possible do not differ for the smallest enterprises. Strikingly, we show that the share of micro firms that are innovators in the sense that they are successfully turning knowledge to productivity, albeit smaller than for small- and medium-sized firms, is positive and far above zero. Future research needs better panel data to find out whether it is in particular the innovative firms among the micro firms that are becoming the future hidden champions. 


\section{References}

Acs, Zoltan J., and David B. Audretsch. 1987. "Innovation, Market Structure, and Firm Size". The Review of Economics and Statistics 69 (4): 567-574.

1988. "Innovation in Large and Small Firms: An Empirical Analysis". The American Economic Review 78 (4): 678-690.

. 1990. "Innovation and Small Firms". Cambridge, MA: MIT Press.

Arnold, Jens Matthias, and Kathrin Hussinger. 2005. "Export Behavior and Firm Productivity in German Manufacturing: A Firm-Level Analysis". Review of World Economics 141 (2): 219-243.

Belderbos, Rene, Martin Carree, and Boris Lokshin. 2004. "Cooperative R\&D and Firm Performance". Research Policy 33 (10): 1477-1492.

Berger, Allen N., and Gregory F. Udell. 2002. "Small Business Credit Availability and Relationship Lending: The Importance of Bank Organisational Structure". The Economic Journal 112 (477): F32-F53.

Chudnovsky, Daniel, Andres Lopez, and German Pupato. 2006. "Innovation and Productivity in Developing Countries: A study of Argentine Manufacturing Firms' Behavior (19922001)". Research Policy 35 (2): 266-288.

Cohen, Wesley M., and Steven Klepper. 1996. "Firm Size and the Nature of Innovation within Industries: The Case of Process and Product R\&D". The Review of Economics and Statistics 78 (2): 232-43.

Cohen, Wesley M., and Richard C. Levin. 1989. "Empirical Studies of Innovation and Market Structure". Chapter 18 in Handbook of Industrial Organization, 1st edition, edited by R. Schmalensee and R. Willig, 2:1059-1107. Elsevier. 
Conte, Andrea, and Marco Vivarelli. 2014. "Succeeding in Innovation: Key Insights on the Role of R\&D and Technological Acquisition Drawn from Company Data". Empirical Economics 47 (4): 1317-1340.

Crepon, Bruno, Emmanuel Duguet, and Jacques Mairesse. 1998. "Research, Innovation and Productivity: An Econometric Analysis at the Firm Level". Economics of Innovation and New Technology 7 (2): 115-158.

Criscuolo, C. 2009. "Innovation and Productivity: Estimating the Core Model Across 18 Countries". In Innovation in Firms: A Microeconomic Perspective, edited by OECD. OECD Publishing.

Czarnitzki, Dirk, and Hanna Hottenrott. 2011. "R\&D Investment and Financing Constraints of Small and Medium-Sized Firms". Small Business Economics 36 (1): 65-83.

Doraszelski, Ulrich, and Jordi Jaumandreu. 2013. "R\&D and Productivity: Estimating Endogenous Productivity". The Review of Economic Studies. doi:10.1093/restud/rdt011. eprint: http://restud. oxfordjournals . org/content/early/2013/03/22/restud . rdt011.full.pdf+html.

European Commission. 2003. "Recommendation 2003/361/EC Concerning the Definition of Small and Medium-sized Enterprises". Official Journal of the European Union L 124: $36-41$.

Evans, David S., and Boyan Jovanovic. 1989. "An Estimated Model of Entrepreneurial Choice under Liquidity Constraints". Journal of Political Economy 97 (4): 808-827.

García-Quevedo, Jóse, Gabriele Pellegrino, and Marco Vivarelli. 2014. "R\&D Drivers and Age: Are Young Firms Different?" Research Policy 43 (9): 1544-1556.

Griffith, Rachel, Elena Huergo, Jacques Mairesse, and Bettina Peters. 2006. "Innovation and Productivity across four European Countries". Oxford Review of Economic Policy 22 (4): 483-498. 
Griliches, Zvi. 1979. "Issues in Assessing the Contribution of Research and Development to Productivity Growth". Bell Journal of Economics 10 (1): 92-116.

Hall, Bronwyn H. 2011. "Innovation and Productivity". Nordic Economic Policy 2:167-204.

Hall, Bronwyn H., Francesca Lotti, and Jacques Mairesse. 2009. "Innovation and Productivity in SMEs: Empirical Evidence for Italy". Small Business Economics 33 (1): 13-33.

Hall, Bronwyn H., Jacques Mairesse, and Pierre Mohnen. 2010. "Measuring the Returns to R\&D". In Handbook of the Economics of Innovation, Volume II, edited by B. H. Hall and N. Rosenberg, 1033-1082. Elsevier B.V.

Halvorsen, Robert, and Raymond Palmquist. 1980. "The Interpretation of Dummy Variables in Semilogarithmic Equations". American Economic Review 70 (3): 474-75.

Harhoff, Dietmar. 1998. "Economics of Innovation and New Technology R\&D and Productivity in German Manufacturing Firms". Economics of Innovation and New Technology 6 (1): 29-49.

Heckman, James. 1979. "Sample Selection Bias as a Specification Error". Econometrica 47 (1): 153-161.

Hirsch, Seev, and Ilan Bijaoui. 1985. "R\&D Intensity and Export Performance: A Micro View". Weltwirtschaftliches Archiv 121 (2): 238-251.

Hoffman, Kurt, Milady Parejo, John Bessant, and Lew Perren. 1998. "Small Firms, R\&D, Technology and Innovation in the UK: a Literature Review". Technovation 18 (1): 39-55.

Janz, Norbert, Hans Lööf, and Bettina Peters. 2004. "Firm Level Innovation and Productivity: Is there a Common Story across Countries?" Problems and Perspectives in Management 2:184-204.

Kennedy, Peter E. 1981. "Estimation with Correctly Interpreted Dummy Variables in Semilogarithmic Equations". American Economic Review 71 (4): 801. 
Kleinknecht, Alfred. 1987. "Measuring R\&D in Small Firms: How much are We Missing?" The Journal of Industrial Economics 36 (2): 253-256.

Lööf, Hans, and Almas Heshmati. 2002. "Knowledge Capital and Performance Heterogeneity: A Firm-Level Innovation Study". International Journal of Production Economics 76 (1): $61-85$.

Mairesse, Jacques, and Jordi Jaumandreu. 2005. "Panel-data Estimates of the Production Function and the Revenue Function: What Difference Does It Make?" Scandinavian Journal of Economics 107 (4): 651-672.

Mairesse, Jacques, and Pierre Mohnen. 2002. "Accounting for Innovation and Measuring Innovativeness: An Illustrative Framework and an Application". American Economic Review 92 (2): 226-230.

. 2010. "Using Innovation Surveys for Econometric Analysis". In Handbook of the Economics of Innovation, edited by B. H. Hall and N. Rosenberg, 1129-1155. Elsevier B.V.

Mohnen, Pierre, and Bronwyn H. Hall. 2013. "Innovation and Productivity: An Update". Eurasian Business Review 3 (1): 47-65.

OECD/Statistical Office of the European Communities, Luxembourg. 2005. "Oslo Manual". OECD Publishing. doi:http://dx.doi.org/10.1787/9789264013100-en.

Pakes, Ariel, and Zvi Griliches. 1984. "Patents and R\&D at the Firm Level: A First Look." In REDD, Patents, and Productivity, 55-71. Chicago: University of Chicago Press.

Parisi, Maria Laura, Fabio Schiantarelli, and Alessandro Sembenelli. 2006. "Productivity, Innovation and R\&D: Micro Evidence for Italy". European Economic Review 50 (8): 2037-2061.

Pavitt, Keith, Michael Robson, and Joe Townsend. 1987. "The Size Distribution of Innovating Firms in the UK: 1945-1983". The Journal of Industrial Economics 35 (3): 297-316. 
Peters, Bettina. 2009. "Persistence of Innovation: Stylised Facts and Panel Data Evidence". The Journal of Technology Transfer 34 (2): 226-243.

Peters, Bettina, Mark J. Roberts, Van Anh Vuong, and Helmut Fryges. 2013. Estimating Dynamic RESD Demand: An Analysis of Costs and Long-Run Benefits, Working Paper Series 19374. National Bureau of Economic Research. doi:10.3386/w19374.

Puhani, Patrick. 2000. "The Heckman Correction for Sample Selection and Its Critique". Journal of Economic Surveys 14 (1): 53-68.

Rammer, Christian, Dirk Czarnitzki, and Alfred Spielkamp. 2009. "Innovation Success of NonR\&D-Performers: Substituting Technology by Management in SMEs". Small Business Economics 33 (1): 35-58.

Santarelli, Enrico, and Alessandro Sterlacchini. 1990. "Innovation, Formal vs. Informal R\&D, and Firm Size: Some Evidence from Italian Manufacturing Firms". Small Business Economics 2 (3): 223-228.

Scherer, F.M., and D. Harhoff. 2000. "Technology Policy for a World of Skew-distributed Outcomes". Research Policy 29 (4-5): 559-566.

Schwartz, Michael. 2013. "KfW-Mittelstandspanel 2012". KfW Bankengruppe.

Stiglitz, Joseph, and Andrew Weiss. 1981. "Credit Rationing in Markets with Imperfect Information". American Economic Review 71 (3): 393-410.

Storey, D.J., and B.S. Tether. 1998. "New Technology-Based Firms in the European Union: an Introduction". Research Policy 26 (9): 933-946.

Vivarelli, Marco. 2015. "Innovation and Employment". IZA World of Labor 154. 


\section{Tables}

Table I: Descriptive statistics by firm size

\begin{tabular}{|c|c|c|c|c|}
\hline & medium 50-249 employees & small 10-49 employees & micro 5-9 employees & micro 0-4 employees \\
\hline Firms & 1881 & 2866 & 1022 & 960 \\
\hline$R \& D$ engagement & 0.60 & 0.41 & 0.28 & 0.19 \\
\hline Innovator share & 0.78 & 0.63 & 0.53 & 0.39 \\
\hline Innovator without $R \& D$ engagement & 0.23 & 0.27 & 0.28 & 0.23 \\
\hline R\&D engagement without innovation & 0.05 & 0.05 & 0.03 & 0.03 \\
\hline Process innovation & 0.58 & 0.42 & 0.32 & 0.21 \\
\hline Product innovation & 0.66 & 0.53 & 0.43 & 0.32 \\
\hline Process innovation only & 0.12 & 0.10 & 0.10 & 0.07 \\
\hline Age class $(<15$ years $)$ & 0.21 & 0.33 & 0.43 & 0.53 \\
\hline Age class (10- 35 years) & 0.31 & 0.33 & 0.30 & 0.27 \\
\hline Age class $(35+$ years $)$ & 0.48 & 0.34 & 0.27 & 0.20 \\
\hline Main sales market: regional & 0.20 & 0.41 & 0.57 & 0.69 \\
\hline Main sales market: national & 0.59 & 0.47 & 0.36 & 0.25 \\
\hline Main sales market: international & 0.21 & 0.12 & 0.07 & 0.05 \\
\hline Public support (yes/no) & 0.39 & 0.47 & 0.55 & 0.62 \\
\hline Group & 0.26 & 0.14 & 0.10 & 0.07 \\
\hline Share of high skilled employees & 0.11 & 0.11 & 0.12 & 0.13 \\
\hline Investment intensity & 8.45 & 8.48 & 8.70 & 9.26 \\
\hline R\&D intensity & 8.20 & 8.41 & 8.71 & 8.68 \\
\hline Labour productivity & 11.77 & 11.63 & 11.50 & 11.43 \\
\hline Observations & 4801 & 7315 & 2419 & 2044 \\
\hline
\end{tabular}

Notes: The table displays the mean. Data are taken from KfW SME panel over the years 2005-2012. Own Calculations. 
Table II: Innovative effort

\begin{tabular}{|c|c|c|c|}
\hline & $\begin{array}{c}\text { Full sample } \\
\beta / \text { s.e. }\end{array}$ & $\begin{array}{c}<10 \text { FTE employees } \\
\beta / \text { s.e. }\end{array}$ & $\begin{array}{c}\geq 10 \mathrm{FTE} \text { employees } \\
\beta / \text { s.e. }\end{array}$ \\
\hline 10-49 employees & $\begin{array}{l}0.309^{* *} \\
(0.05)\end{array}$ & & \\
\hline 5-9 employees & $\begin{array}{c}0.639^{* *} \\
(0.07)\end{array}$ & & \\
\hline 0-4 employees & $\begin{array}{c}0.650^{* *} \\
(0.11)\end{array}$ & & \\
\hline Age class (15-35 years) & $\begin{array}{l}0.063 \\
(0.05)\end{array}$ & $\begin{array}{l}0.236^{*} \\
(0.12)\end{array}$ & $\begin{array}{l}0.039 \\
(0.05)\end{array}$ \\
\hline Age class $(35+$ years $)$ & $\begin{array}{c}-0.151^{* *} \\
(0.05)\end{array}$ & $\begin{array}{r}-0.146 \\
(0.16)\end{array}$ & $\begin{array}{c}-0.150^{* *} \\
(0.06)\end{array}$ \\
\hline Group & $\begin{array}{c}0.144^{* *} \\
(0.05)\end{array}$ & $\begin{array}{c}0.453^{* *} \\
(0.12)\end{array}$ & $\begin{array}{l}0.106^{*} \\
(0.05)\end{array}$ \\
\hline Public support & $\begin{array}{l}0.007 \\
(0.03)\end{array}$ & $\begin{array}{l}-0.162 \\
(0.08)\end{array}$ & $\begin{array}{l}0.035 \\
(0.03)\end{array}$ \\
\hline Main sales market: national & $\begin{array}{c}0.460^{* *} \\
(0.05)\end{array}$ & $\begin{array}{c}0.494^{* *} \\
(0.11)\end{array}$ & $\begin{array}{c}0.437^{* *} \\
(0.06)\end{array}$ \\
\hline Main sales market: international & $\begin{array}{l}0.806^{* *} \\
(0.06)\end{array}$ & $\begin{array}{c}0.880^{* *} \\
(0.14)\end{array}$ & $\begin{array}{l}0.798^{* *} \\
(0.07)\end{array}$ \\
\hline Employees & & $\begin{array}{l}-0.014 \\
(0.02)\end{array}$ & $\begin{array}{c}-0.003^{* *} \\
(0.00)\end{array}$ \\
\hline Industry & Yes & Yes & Yes \\
\hline Year & Yes & Yes & Yes \\
\hline Region & Yes & Yes & Yes \\
\hline Observations & 6631 & 1021 & 5610 \\
\hline Adjusted $R^{2}$ & 0.150 & 0.170 & 0.135 \\
\hline
\end{tabular}

Note: Significance at ${ }^{*} \mathrm{p}<.05,{ }^{* *} \mathrm{p}<.01$ level. Clustered s.e. at the firm level in parentheses. Reference groups: Medium-sized firm (Column 1 only), Age class $<15$ Years, Main sales market: regional. 
Table III: Full sample: Knowledge production function

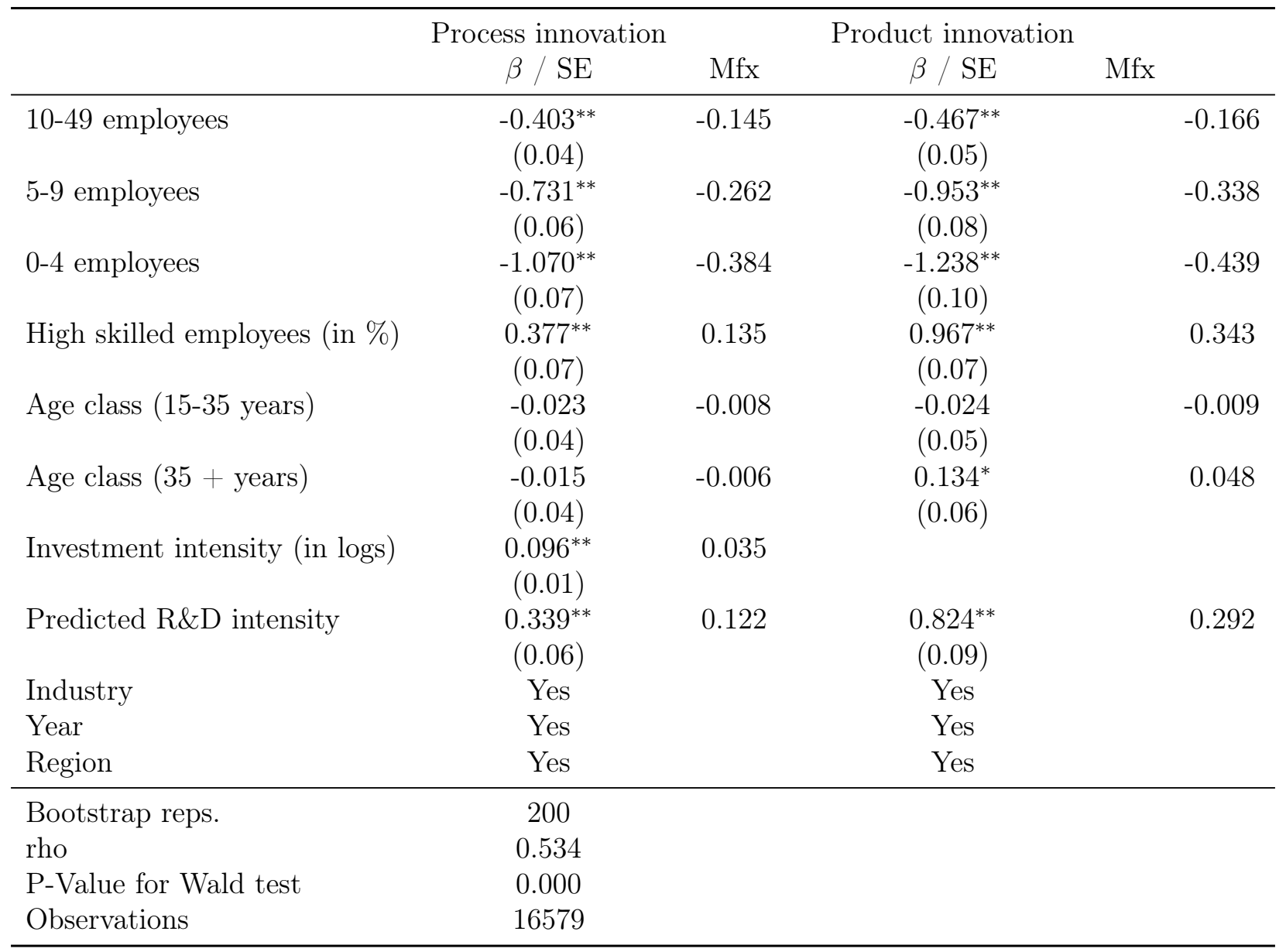

Note: Significance at ${ }^{*} \mathrm{p}<.05,{ }^{*} * \mathrm{p}<.01$ level. Clustered s.e. at the firm level in parentheses. Reference groups: Medium-sized firm, Age class $<15$ Years. Mfx denotes average marginal effects. 
Table IV: < 10 FTE employees: Knowledge production function

\begin{tabular}{|c|c|c|c|c|}
\hline & $\begin{array}{c}\text { Process innovation } \\
\beta / \mathrm{SE}\end{array}$ & Mfx & $\begin{array}{c}\text { Product innovation } \\
\beta / \mathrm{SE}\end{array}$ & Mfx \\
\hline Employees & $\begin{array}{c}0.068^{* *} \\
(0.01)\end{array}$ & 0.020 & $\begin{array}{c}0.075^{* *} \\
(0.02)\end{array}$ & 0.024 \\
\hline High skilled employees (in \%) & $\begin{array}{c}0.405^{* *} \\
(0.09)\end{array}$ & 0.124 & $\begin{array}{c}0.625^{* *} \\
(0.09)\end{array}$ & 0.218 \\
\hline Age class (15-35 years) & $\begin{array}{c}-0.243^{* *} \\
(0.07)\end{array}$ & -0.058 & $\begin{array}{c}-0.287^{* *} \\
(0.11)\end{array}$ & -0.061 \\
\hline Age class $(35+$ years $)$ & $\begin{array}{r}-0.017 \\
(0.11)\end{array}$ & 0.000 & $\begin{array}{r}-0.027 \\
(0.15)\end{array}$ & -0.005 \\
\hline Investment intensity (in logs) & $\begin{array}{c}0.057^{* *} \\
(0.02)\end{array}$ & 0.017 & & \\
\hline Predicted R\&D intensity & $\begin{array}{c}0.363^{* *} \\
(0.10)\end{array}$ & 0.145 & $\begin{array}{c}0.735^{* *} \\
(0.14)\end{array}$ & 0.295 \\
\hline Industry & Yes & & Yes & \\
\hline Year & Yes & & Yes & \\
\hline Region & Yes & & Yes & \\
\hline $\begin{array}{l}\text { Bootstrap reps. } \\
\text { rho } \\
\text { P-Value for Wald test } \\
\text { Observations }\end{array}$ & $\begin{array}{c}200 \\
0.551 \\
0.000 \\
4463\end{array}$ & & & \\
\hline
\end{tabular}

Note: Significance at ${ }^{*} \mathrm{p}<.05,{ }^{* *} \mathrm{p}<.01$ level. Clustered s.e. at the firm level in parentheses. Reference group: Age class $<15$ Years. Mfx denotes average marginal effects. 
Table V: $\geq 10$ FTE employees: Knowledge production function

\begin{tabular}{|c|c|c|c|c|}
\hline & $\begin{array}{c}\text { Process innovation } \\
\beta / \mathrm{SE}\end{array}$ & Mfx & $\begin{array}{l}\text { Product innovation } \\
\qquad \beta / \mathrm{SE}\end{array}$ & Mfx \\
\hline Employees & $\begin{array}{c}0.004^{* *} \\
(0.00)\end{array}$ & 0.002 & $\begin{array}{c}0.005^{* *} \\
(0.00)\end{array}$ & 0.001 \\
\hline High skilled employees (in \%) & $\begin{array}{c}0.367^{* *} \\
(0.11)\end{array}$ & 0.143 & $\begin{array}{c}1.503^{* *} \\
(0.12)\end{array}$ & 0.543 \\
\hline Age class (15-35 years) & $\begin{array}{l}0.024 \\
(0.04)\end{array}$ & 0.008 & $\begin{array}{l}0.053 \\
(0.06)\end{array}$ & 0.015 \\
\hline Age class $(35+$ years $)$ & $\begin{array}{r}-0.032 \\
(0.04)\end{array}$ & -0.016 & $\begin{array}{c}0.180^{* *} \\
(0.07)\end{array}$ & 0.059 \\
\hline Investment intensity (in logs) & $\begin{array}{c}0.108^{* *} \\
(0.01)\end{array}$ & 0.041 & & \\
\hline Predicted R\&D intensity & $\begin{array}{c}0.277^{* *} \\
(0.06)\end{array}$ & 0.079 & $\begin{array}{c}0.780^{* *} \\
(0.09)\end{array}$ & 0.236 \\
\hline Industry & Yes & & Yes & \\
\hline Year & Yes & & Yes & \\
\hline Region & Yes & & Yes & \\
\hline $\begin{array}{l}\text { Bootstrap reps. } \\
\text { rho } \\
\text { P-Value for Wald test } \\
\text { Observations }\end{array}$ & $\begin{array}{c}200 \\
0.531 \\
0.000 \\
12116\end{array}$ & & & \\
\hline
\end{tabular}

Note: Significance at ${ }^{*} \mathrm{p}<.05,{ }^{* *} \mathrm{p}<.01$ level. Clustered s.e. at the firm level in parentheses. Reference group: Age class $<15$ Years. Mfx denotes average marginal effects. 
Table VI: Production function

\begin{tabular}{lccc}
\hline & $\begin{array}{c}\text { Full sample } \\
\mathrm{b} / \mathrm{se}\end{array}$ & $\begin{array}{c}<10 \mathrm{FTE} \text { employess } \\
\mathrm{b} / \mathrm{se}\end{array}$ & $\begin{array}{c}\text { FTE employees } \\
\mathrm{b} / \mathrm{se}\end{array}$ \\
\hline 10-49 employees & $0.117^{*}$ & & \\
& $(0.05)$ & & \\
5 -9 employees & 0.152 & & \\
& $(0.08)$ & & \\
0-4 employees & $0.242^{*}$ & & -0.011 \\
& $(0.12)$ & $0.195^{* *}$ & $(0.02)$ \\
Age class (15-35 years) & $0.069^{* *}$ & $(0.05)$ & 0.020 \\
& $(0.02)$ & $0.303^{* *}$ & $(0.05)$ \\
Age class (35 + years) & $0.097^{* *}$ & $(0.05)$ & 0.072 \\
& $(0.03)$ & $0.241^{* *}$ & $(0.05)$ \\
Investment intensity (in logs) & $0.100^{* *}$ & $(0.03)$ & $1.275^{* *}$ \\
& $(0.02)$ & $2.610^{* *}$ & $(0.36)$ \\
Product Innovation & $1.258^{* *}$ & $(0.67)$ & 0.394 \\
& $(0.30)$ & -1.878 & $(1.11)$ \\
Process Innovation & 0.415 & $(1.14)$ & -0.001 \\
& $(0.64)$ & -0.014 & $(0.00)$ \\
Employees & & $(0.01)$ & Yes \\
Industry & & Yes & Yes \\
Year dummy & Yes & Yes & Yes \\
Region & Yes & Yes & 12116 \\
\hline Observations & 16579 & 4463 & 200 \\
Bootstrap reps. & 200 & 200 & 0.169 \\
Adj. Rsq & 0.167 & 0.158 & \\
\hline
\end{tabular}

Note: Significance at ${ }^{*} \mathrm{p}<.05,{ }^{* *} \mathrm{p}<.01$ level. Clustered s.e. at the firm level in parenthesis. Reference groups: Medium-sized firm (Column 1 only), Age class $<15$ Years. 


\section{$9 \quad$ Figures}

Figure 1: Size distribution and share of innovators

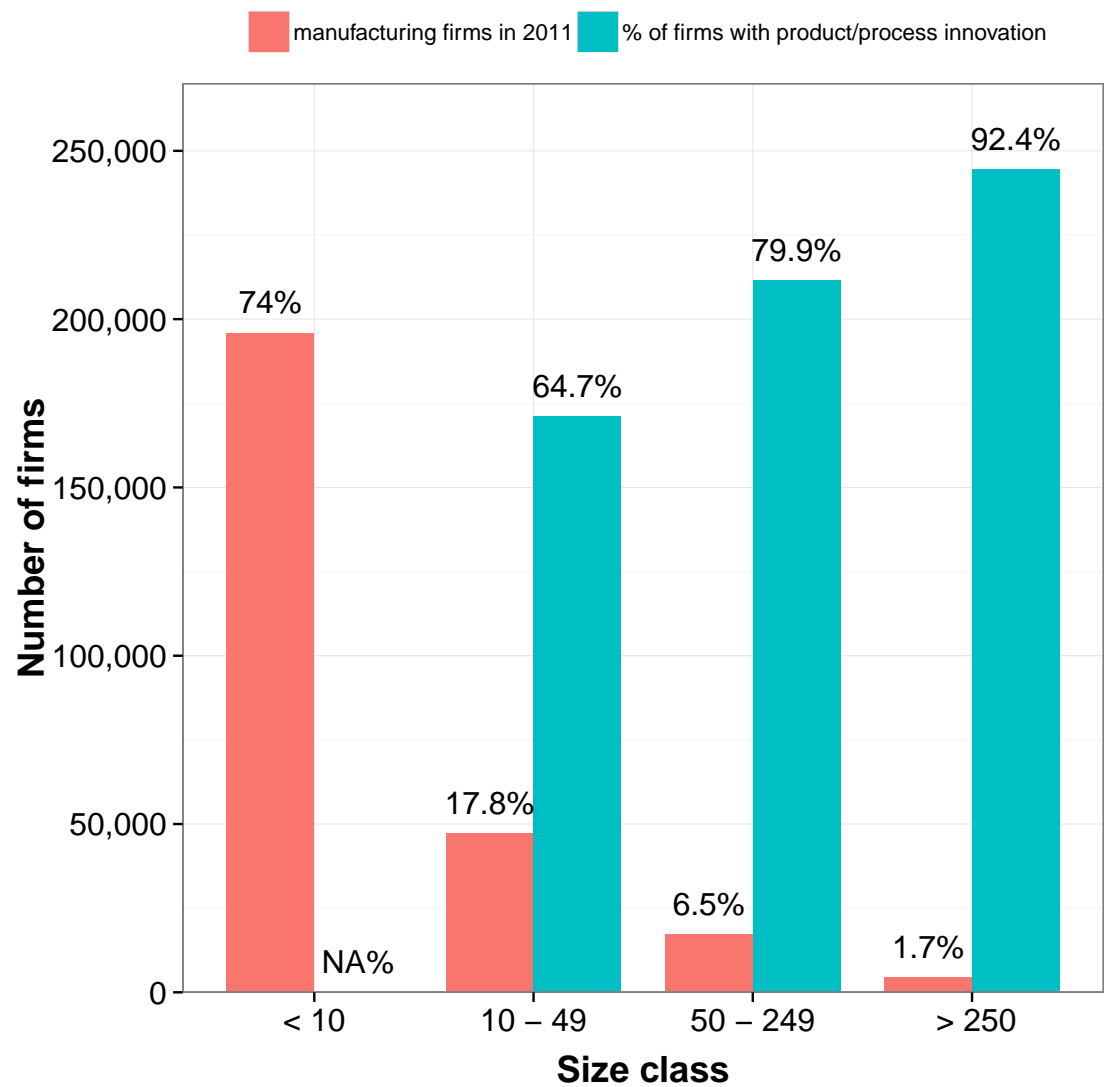

Sources: Business register (Destatis) for number of manufacturing firms in 2011, Community Innovation Surveys (CIS) 7 for share of innovators among German firms. 


\section{A Appendix}

\section{Table A1: Variable description}

\begin{tabular}{ll}
\hline Variables & Description \\
\hline $0-4 / 5-9 /$ small/medium firms & Indicators for firm size 0-4/5-9/10-49/50-249 full time equivalent (FTE) employees \\
Employees & Number of FTE employees \\
R\&D engagement & Binary variable equal to 1 if the firm reports a continuous/occasional R\&D engagement \\
& (within the last three years) \\
R\&D intensity & R\&D expenditures per FTE employee in logs (last year) \\
Product innovation & (winary variable equal to 1 if the firm reports the introduction of a product innovation \\
& Binary variable equal to 1 if the firm reports the introduction of a process innovation \\
Process innovation & (within the last three years) \\
Innovator & Binary variable equal to 1 if firm reports a product and/ or process innovation \\
Public support & Binary variable equal to 1 if firm has received subsidies (last year) \\
Regional/National/International & Dummy variable that indicates the location of the main sales market (last year) \\
Age class & Dummy variable that indicates the firm's age class \\
Group & Binary variable equal to 1 if other firms hold over 25\% of the shares \\
High skilled employees & Share of employees with a university degree (last year) \\
Investment intensity & Investment in machinery per FTE employee, in logs (last year) \\
Industry dummies & Indicators for a two-digit industry classification \\
Year dummies & Indicators for the year of the survey \\
Region & Dummy for East/West Germany \\
Labor productivity & Sales per FTE employee, in logs (last year) \\
\hline
\end{tabular}


Table A2: Innovative effort: Sample Selection

\begin{tabular}{|c|c|c|c|}
\hline & $\begin{array}{c}\text { Full Sample } \\
\beta / \text { s.e. }\end{array}$ & $\begin{array}{c}<10 \text { FTE employees } \\
\beta / \text { s.e. }\end{array}$ & $\begin{array}{c}\geq 10 \mathrm{FTE} \text { employees } \\
\beta / \text { s.e. }\end{array}$ \\
\hline \multicolumn{4}{|l|}{ R\&D intensity } \\
\hline 10-49 employees & $\begin{array}{c}0.319^{* *} \\
(0.07)\end{array}$ & & \\
\hline 5-9 employees & $\begin{array}{c}0.659^{* *} \\
(0.12)\end{array}$ & & \\
\hline 0-4 employees & $\begin{array}{c}0.683^{* *} \\
(0.20)\end{array}$ & & \\
\hline Age class (15-35 years) & $\begin{array}{l}0.062 \\
(0.04)\end{array}$ & $\begin{array}{l}0.281 \\
(0.17)\end{array}$ & $\begin{array}{l}0.091 \\
(0.06)\end{array}$ \\
\hline Age class $(35+$ years $)$ & $\begin{array}{c}-0.148^{* *} \\
(0.04)\end{array}$ & $\begin{array}{l}-0.097 \\
(0.19)\end{array}$ & $\begin{array}{c}-0.134^{* *} \\
(0.04)\end{array}$ \\
\hline Group & $\begin{array}{c}0.141^{* *} \\
(0.04)\end{array}$ & $\begin{array}{l}0.413^{*} \\
(0.18)\end{array}$ & $\begin{array}{c}0.158^{* *} \\
(0.05)\end{array}$ \\
\hline Public support & $\begin{array}{l}0.011 \\
(0.04)\end{array}$ & $\begin{array}{l}-0.080 \\
(0.27)\end{array}$ & $\begin{array}{l}-0.001 \\
(0.04)\end{array}$ \\
\hline Main sales market: national & $\begin{array}{l}0.425^{*} \\
(0.21)\end{array}$ & $\begin{array}{l}0.203 \\
(0.93)\end{array}$ & $\begin{array}{c}0.847^{* *} \\
(0.29)\end{array}$ \\
\hline Main sales market: international & $\begin{array}{l}0.750^{*} \\
(0.33)\end{array}$ & $\begin{array}{l}0.422 \\
(1.46)\end{array}$ & $\begin{array}{c}1.458^{* *} \\
(0.47)\end{array}$ \\
\hline Employees & & $\begin{array}{r}-0.014 \\
(0.02)\end{array}$ & $\begin{array}{c}-0.003^{* *} \\
(0.00)\end{array}$ \\
\hline \multicolumn{4}{|l|}{ R\&D selection } \\
\hline 10-49 employees & $\begin{array}{c}-0.260^{* *} \\
(0.03)\end{array}$ & & \\
\hline 5-9 employees & $\begin{array}{c}-0.456^{* *} \\
(0.04)\end{array}$ & & \\
\hline 0-4 employees & $\begin{array}{c}-0.722^{* *} \\
(0.04)\end{array}$ & & \\
\hline Age class (15-35 years) & $\begin{array}{l}0.017 \\
(0.03)\end{array}$ & $\begin{array}{c}-0.136^{*} \\
(0.05)\end{array}$ & $\begin{array}{c}0.108^{* *} \\
(0.03)\end{array}$ \\
\hline Age class $(35+$ years $)$ & $\begin{array}{c}-0.075^{* *} \\
(0.03)\end{array}$ & $\begin{array}{r}-0.143^{*} \\
(0.06)\end{array}$ & $\begin{array}{l}0.033 \\
(0.03)\end{array}$ \\
\hline Group & $\begin{array}{l}0.066^{*} \\
(0.03)\end{array}$ & $\begin{array}{l}0.124 \\
(0.08)\end{array}$ & $\begin{array}{c}0.110^{* *} \\
(0.03)\end{array}$ \\
\hline Public support & $\begin{array}{c}-0.102^{* *} \\
(0.02)\end{array}$ & $\begin{array}{c}-0.245^{* *} \\
(0.05)\end{array}$ & $\begin{array}{c}-0.076^{* *} \\
(0.02)\end{array}$ \\
\hline Main sales market: national & $\begin{array}{c}0.700^{* *} \\
(0.02)\end{array}$ & $\begin{array}{c}0.801^{* *} \\
(0.05)\end{array}$ & $\begin{array}{c}0.727^{* *} \\
(0.03)\end{array}$ \\
\hline Main sales market: international & $\begin{array}{c}1.280^{* *} \\
(0.04)\end{array}$ & $\begin{array}{c}1.376^{* *} \\
(0.09)\end{array}$ & $\begin{array}{c}1.314^{* *} \\
(0.04)\end{array}$ \\
\hline \multicolumn{4}{|l|}{ mills } \\
\hline lambda & $\begin{array}{l}-0.069 \\
(0.40)\end{array}$ & $\begin{array}{l}-0.478 \\
(1.52)\end{array}$ & $\begin{array}{l}0.811 \\
(0.57)\end{array}$ \\
\hline Industry & Yes & Yes & Yes \\
\hline Year & Yes & Yes & Yes \\
\hline Region & Yes & Yes & Yes \\
\hline Observations & 16579 & 4463 & 12116 \\
\hline
\end{tabular}


Table A3: Full sample robustness check: investment intensity Stage 2

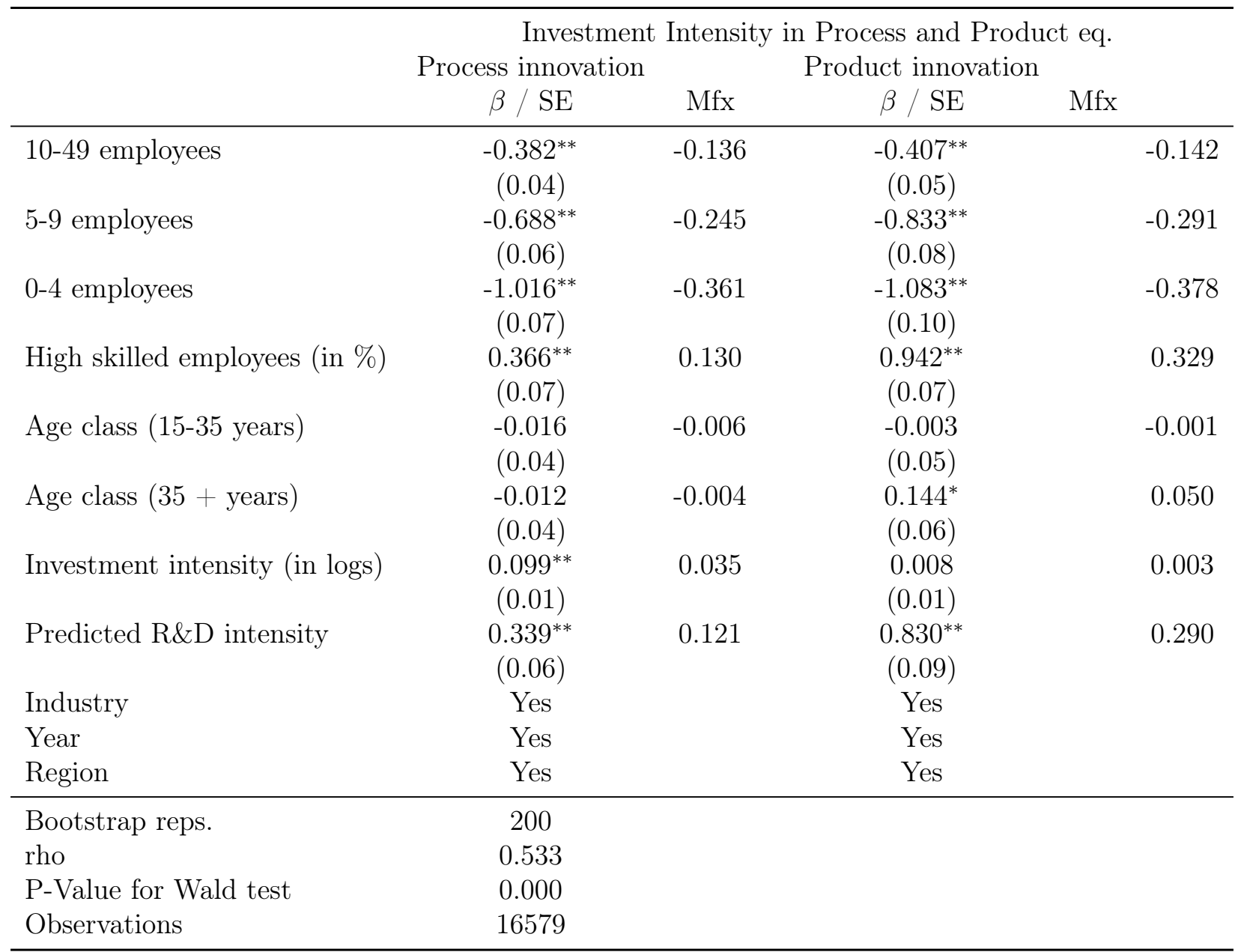

Note: Significance at ${ }^{*} \mathrm{p}<.05,{ }^{*} * \mathrm{p}<.01$ level. Clustered s.e. at the firm level in parenthesis. Reference groups: Medium-sized firm, Age class $<15$ Years. Mfx denotes average marginal effects. 
Table A4: Full sample: Probit Innovator

\begin{tabular}{lcc}
\hline \hline & $\beta / \mathrm{SE}$ & $\mathrm{Mfx}$ \\
\hline Innovator & $-0.479^{* *}$ & -0.156 \\
10-49 employees & $(0.05)$ & \\
& $-0.883^{* *}$ & -0.287 \\
5-9 employees & $(0.08)$ & \\
& $-1.207^{* *}$ & -0.393 \\
0-4 employees & $(0.10)$ & \\
& $0.909^{* *}$ & 0.296 \\
High skilled employees (in \%) & $(0.07)$ & \\
& -0.009 & -0.003 \\
Age class (15-35 years) & $(0.05)$ & \\
& $0.135^{*}$ & 0.044 \\
Age class (35 + years) & $(0.06)$ & \\
& $0.052^{* *}$ & 0.017 \\
Investment intensity (in logs) & $(0.01)$ & \\
& $0.749^{* *}$ & 0.244 \\
Predicted R\&D intensity & $(0.09)$ & \\
Industry & Yes & \\
Year & Yes & \\
Region & Yes & \\
\hline Bootstrap reps. & 200 & \\
Observations & 16579 & \\
\hline \hline
\end{tabular}

Note: Significance at $* \mathrm{p}<.05,{ }^{* *} \mathrm{p}<.01$ level. Clustered s.e. at the firm level in parenthesis. Reference groups: Medium-sized firm, Age class $<15$ Years. Mfx denotes average marginal effects. 
Table A5: <10 FTE employees: Probit Innovator

\begin{tabular}{lcc}
\hline \hline & $\beta / \mathrm{SE}$ & $\mathrm{Mfx}$ \\
\hline Innovator & $0.080^{* *}$ & 0.028 \\
Employees & $(0.02)$ & \\
& $0.687^{* *}$ & 0.243 \\
High skilled employees (in \%) & $(0.10)$ & \\
& $-0.289^{* *}$ & -0.102 \\
Age class (15-35 years) & $(0.10)$ & \\
& 0.034 & 0.012 \\
Age class (35 + years) & $(0.15)$ & \\
& $0.079^{* *}$ & 0.028 \\
Investment intensity (in logs) & $(0.02)$ & \\
& $0.643^{* *}$ & 0.228 \\
Predicted R\&D intensity & $(0.13)$ & \\
& Yes & \\
Industry & Yes & \\
Year & Yes & \\
Region & 200 & \\
\hline Bootstrap reps. & 4463 & \\
Observations & \\
\hline \hline
\end{tabular}

Note: Significance at ${ }^{*} \mathrm{p}<.05,{ }^{* *} \mathrm{p}<.01$ level. Clustered s.e. at the firm level in parenthesis. Reference group: Age class $<15$ Years. Mfx denotes average marginal effects. 
Table A6: $\geq 10$ FTE employees: Probit Innovator

\begin{tabular}{lcc}
\hline \hline & $\beta / \mathrm{SE}$ & $\mathrm{Mfx}$ \\
\hline Innovator & & \\
Employees & $0.005^{* *}$ & 0.002 \\
& $(0.00)$ & \\
High skilled employees (in \%) & $1.292^{* *}$ & 0.405 \\
& $(0.13)$ & \\
Age class (15-35 years) & 0.073 & 0.023 \\
& $(0.05)$ & \\
Age class (35 + years) & $0.157^{*}$ & 0.049 \\
& $(0.06)$ & \\
Investment intensity (in logs) & $0.049^{* *}$ & 0.015 \\
& $(0.01)$ & \\
Predicted R\&D intensity & $0.710^{* *}$ & 0.223 \\
& $(0.09)$ & \\
Industry & Yes & \\
Year & Yes & \\
Region & Yes & \\
\hline Bootstrap reps. & 200 & \\
Observations & 12116 & \\
\hline \hline
\end{tabular}

Note: Significance at $* \mathrm{p}<.05,{ }^{* *} \mathrm{p}<.01$ level. Clustered s.e. at the firm level in parenthesis. Reference group: Age class $<15$ Years. Mfx denotes average marginal effects. 
Table A7: Production function

\begin{tabular}{|c|c|c|c|}
\hline & $\begin{array}{l}\text { Full sample } \\
\text { b/se }\end{array}$ & $\begin{array}{c}<10 \text { FTE employess } \\
\text { b/se }\end{array}$ & $\begin{array}{c}\geq 10 \mathrm{FTE} \text { employees } \\
\mathrm{b} / \mathrm{se}\end{array}$ \\
\hline 10-49 employees & $\begin{array}{c}0.093^{* *} \\
(0.02)\end{array}$ & & \\
\hline 5-9 employees & $\begin{array}{l}0.090^{*} \\
(0.04)\end{array}$ & & \\
\hline 0-4 employees & $\begin{array}{c}0.204^{* *} \\
(0.06)\end{array}$ & & \\
\hline Age class (15-35 years) & $\begin{array}{c}0.060^{* *} \\
(0.02)\end{array}$ & $\begin{array}{c}0.256^{* *} \\
(0.04)\end{array}$ & $\begin{array}{l}-0.024 \\
(0.02)\end{array}$ \\
\hline Age class $(35+$ years $)$ & $\begin{array}{c}0.078^{* *} \\
(0.02)\end{array}$ & $\begin{array}{c}0.251^{* *} \\
(0.05)\end{array}$ & $\begin{array}{l}0.008 \\
(0.03)\end{array}$ \\
\hline Investment intensity (in logs) & $\begin{array}{c}0.087^{* *} \\
(0.01)\end{array}$ & $\begin{array}{c}0.162^{* *} \\
(0.02)\end{array}$ & $\begin{array}{c}0.060^{* *} \\
(0.01)\end{array}$ \\
\hline Innovator probit & $\begin{array}{c}1.635^{* *} \\
(0.12)\end{array}$ & $\begin{array}{c}1.774^{* *} \\
(0.24)\end{array}$ & $\begin{array}{c}1.717^{* *} \\
(0.11)\end{array}$ \\
\hline Employees & & $\begin{array}{c}-0.033^{* *} \\
(0.01)\end{array}$ & $\begin{array}{c}-0.001^{* *} \\
(0.00)\end{array}$ \\
\hline Industry & Yes & Yes & Yes \\
\hline Year dummy & Yes & Yes & Yes \\
\hline Region & Yes & Yes & Yes \\
\hline Observations & 16579 & 4463 & 12116 \\
\hline Bootstrap reps. & 200 & 200 & 200 \\
\hline Adj. Rsq & 0.166 & 0.160 & 0.173 \\
\hline
\end{tabular}

Note: Significance at ${ }^{*} \mathrm{p}<.05,{ }^{* *} \mathrm{p}<.01$ level. Clustered s.e. at the firm level in parenthesis. Reference groups: Medium-sized firm (Column 1 only), Age class $<15$ Years. 